\title{
Reponse attributes and anxiety (drive) in paired associate learning
}

\author{
S. v. PETZEL \\ University of Minnesota, Minneapolis, Minnesota 55455 \\ and \\ ROBERT L. SOLSO \\ University of Idaho, Moscow, Idaho 83843
}

\begin{abstract}
The effect of generalized drive (measured by the Taylor Manifest Anxiety Scale), meaningfulness, and similarity was examined in a paired associate learning task. Learning was analyzed in two stages, a response-learning (RL) and an associative-matching (AM) stage. The task varied in intralist response similarity and interlist response meaningfulness. Contrary to expectation, the interaction between anxiety and response similarity was not significant. Under conditions of high meaningfulness, low similarity had a facilitatory effect on RL and AM. The results were not predicted by the Taylor-Spence drive theory.
\end{abstract}

Since the early 1950 s, the relationship between level of drive and performance in a variety of learning situations has been investigated. Many of these studies tested hypotheses originally formulated by Spence $(1956,1958)$ and Taylor $(1953,1956)$ related to the effects of anxiety as drive on complex learning. Drive in these studies was measured in terms of extreme scores on the Manifest Anxiety Scale (MAS) (Taylor, 1953). Results using a paired associates (PA) task have supported (Taylor, 1958; Taylor \& Chapman, 1955) and failed to support (L'Abate, 1959; Levitt \& Goss, 1961) hypotheses based on the Taylor-Spence drive theory.

The development of stage analysis of PA learning (Underwood, Runquist, \& Schulz, 1959; Underwood \& Schulz, 1960) has led to the inference that deleterious effects of response competition in a verbal task will be localized in the associative rather than the responselearning stage (Horowitz, 1962; Jung, 1965; Underwood \& Schultz, 1960). Based on Taylor-Spence formulations, Goulet (1968) predicted that with a high-similarity stimulus/low-similarity response list, the performance of low-anxious (LA) subjects will exceed that of highanxious (HA) subjects up to the point where the correct response to each stimulus attains dominance. With a low-similarity stimulus/high-similarity response list, Goulet predicted HA subjects would be superior to LA subjects in response acquisition, but the associative stage would be hindered for HA subjects. Experimental results can be found that support (Taylor \& Chapman, 1955) and fail to support (L'Abate, 1959; Levitt \& Goss, 1961) Goulet's predictions.

The purpose of the present study was to test the notion that in PA learning in which the correct response to each stimulus is not dominant and response competition is high (low-similarity stimulus/high-similarity response list), increased drive (anxiety) will be accompanied by facilitation of response learning (relative to a low-similarity stimulus/low-similarity response list) and integration of one response will generalize to each of the remaining responses.

\section{EXPERIMENT 1}

\section{Method}

Design and Procedure. A factorial design (similarity by anxiety by recall condition by trials) was used in which stimulus terms were two-digit numbers and response terms were "nonsense" syllables of high and low formal similarity. Subjects at each level of anxiety were equally divided into two conditions of response similarity. Two equivalent response sets at each level of similarity were used. Nonsense syllables consisted of consonant-vowel-consonant (CVC) combinations having Glaze (1928) values of $93.3 \%$ and $100 \%$ (high association value). High intralist similarity was established within each list by using five vowels and four different consonants. Low intralist similarity was established within each list by using five vowels and 20 consonants. Four 10-pair lists were used. One set of twodigit numbers having moderate association value (Battig \& Spera, 1962) was used as the stimulus terms in all response-term variations.

Subjects were given 15 trials and spelled anticipated nonsense-syllable responses. Two recall measures, a responserecall (RL) and an associative-matching (AM) condition, were called for from all subjects after Trials $3,6,9$, and 15 . In the RL condition, subjects wrote as many responses as could be recalled within $60 \mathrm{sec}$. In the AM condition, subjects matched responses written on cards with a list of correct stimuli. Response learning was measured by the number of correct responses listed during free recall following Trials 3, 6, 9, and 15. Associative matching was measured by the number of responses correctly matched following Trials 3,6, 9, and 15. Overall PA learning was measured by the number of correctly anticipated responses on the 14 anticipation trials.

Paired associate lists were presented at a $2.2-\mathrm{sec}$ rate with a 4-sec intertrial interval. Prior to the main task, subjects had a practice task with three pairs consisting of single-digit stimuli and word responses. All subjects saw one demonstration pair 
representing the type of experimental list they were to learn and received "stress" instructions similar to those reported by Spielberger (1966).

Subjects. The subjects were selected from a pool of 532 students enrolled in an introductory psychology course who volunteered to complete the MAS. This scale was called "Biographic Inventory" and contained 40 buffers in addition to the 50 items of the test. The subjects were divided into HA, MA, and LA groups, with the HA group composed of subjects in the middle $36 \%$ of MAS scores, and the LA group composed of subjects in the lower $25 \%$ of MAS scores. The median MAS score for the HA group was 26, the MA group, 14.5, and the LA group, 9. One hundred and twenty subjects (40 HA, 40 MA, 40 LA) were equally distributed throughout six cells of a factorial arrangement. Cells were matched according to sex, and subjects were alternately assigned to an experimental condition upon appearance in the laboratory.

\section{Results}

Response learning (RL) and associative learning (AM). Analysis of variance (similarity by anxiety by recall condition by trials) of means on three RL and AM trials showed a significant main effect for anxiety $(\mathrm{F}=4.91, \mathrm{p}<.01)$. With the exception of the Trial by Similarity interaction under conditions of AM, none of the main effects or interactions in either learning condition were significant at or beyond the .05 level. These trends are illustrated in Figure 1.

Overall PA learning. Differences among means for successive three-trial blocks were assessed by a threeway analysis of variance (similarity by anxiety by trials). None of the main effects or interactions were significant at or beyond the .05 level.

\section{EXPERIMENT 2}

\section{Method}

Procedure. The procedure was the same as in Experiment 1 except words were used as response members. All response

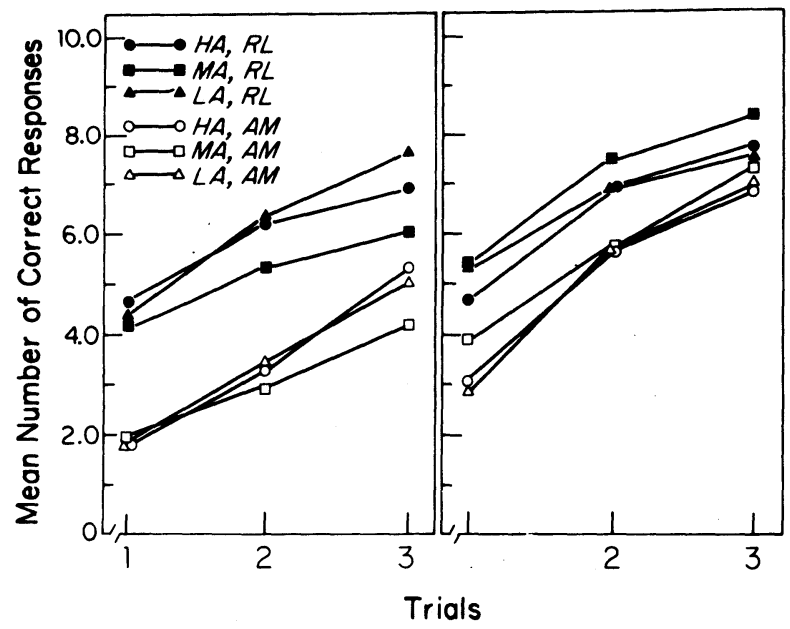

Figure 1. Means of correct responses for response-learning (RL) and associative-learning (AM) stages on test Trials 1, 2, and 3 for combinations of high (HA), moderate (MA), and low (LA) anxiety with lists of each variation of intralist response similarity: high (HS) (left) and low (LS) (right), Experiment 1.

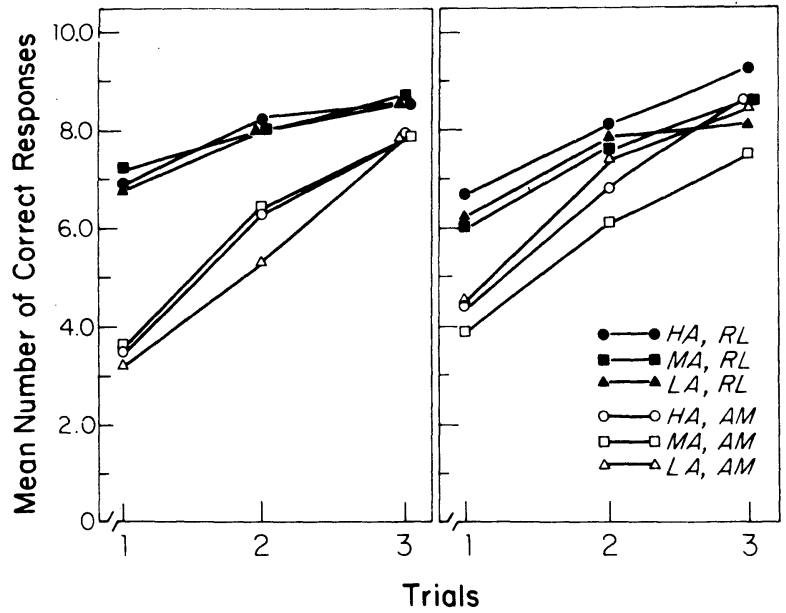

Figure 2. Means of correct responses for response-learning (RL) and associative-learning (AM) stages on test Trials 1, 2, and 3 for combinations of high (HA), moderate (MA), and low (LA) anxiety with lists of each variation of intralist response similarity: high (HS) (left) and low (LS) (right), Experiment 2.

words were one- and two-syllable nouns having a frequency of $5-25 /$ million based on the Thorndike-Lorge (1944) count. Responses varied on the basis of high and low conceptual similarity. Two equivalent response sets of words of high intralist similarity and two equivalent response sets of words of low intralist similarity were used. High-similarity (HS) items consisted of words having a high level of conceptual similarity based upon the Battig and Montague (1969) norms. Ten words were selected from each of two categories, Categories 8 and 37. Each low-similarity (LS) word list consisted of 10 nouns, each of which was selected from a different Battig and Montague category. Subjects were given 15 trials and pronounced anticipated words as responses.

Subjects. One hundred and twenty introductory psychology students (40 HA, 40 MA, 40 LA) were selected and distributed throughout six cells of a factorial arrangement as in Experiment 1.

\section{Results}

Response learning and associative learning. Analysis of variance (similarity by anxiety by recall condition by trials) of means on the three RL and AM trials showed a significant main effect for similarity $(F=4.67, p<.05)$ and for anxiety $(F=5.16, p<.01)$. Similarity, anxiety, recall condition, and test trials entered into five interactions significant at the .05 level or beyond, illustrated in Figure 2. Significant interactions indicated in the four-way analysis of variance were further examined by two three-way analyses of variance (similarity by anxiety by trials). With the exception of the Trial by Anxiety interaction under conditions of $\mathrm{AM}(\mathrm{F}=3.11, \mathrm{p}<.05)$, none of the main effects or interactions were significant at or beyond the .05 level.

Overall PA learning. Differences among means for successive three-trial blocks were assessed by a three-way analysis of variance (similarity by anxiety by trials). The main effects for similarity and anxiety and their interaction were not significant. The Fs for trials and for 


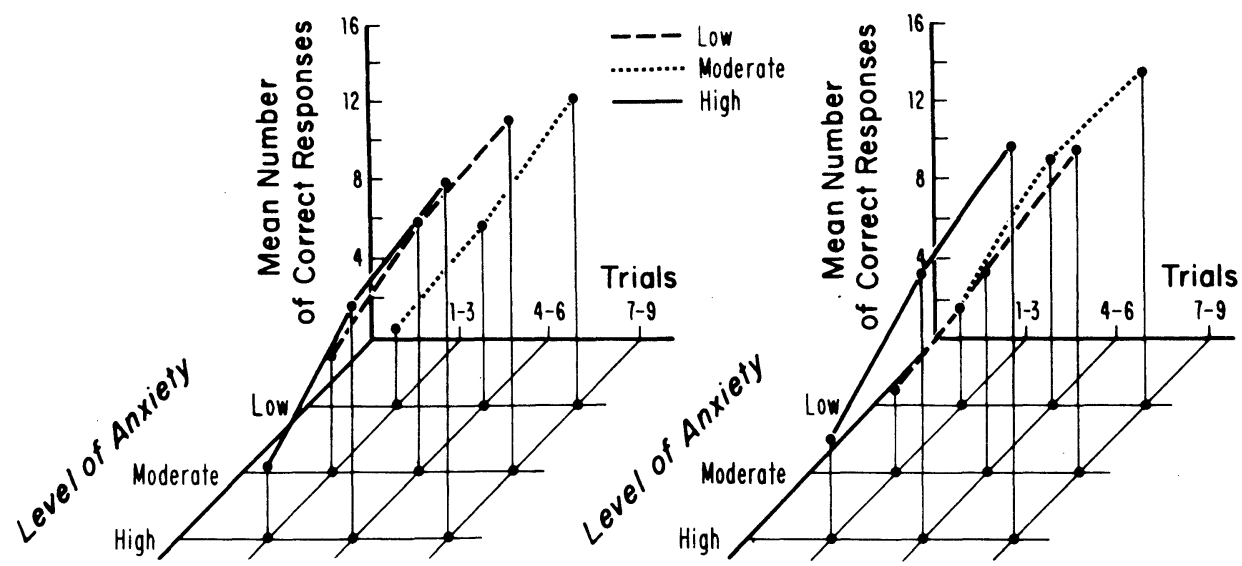

Figure 3. Means of correct anticipated responses in successive blocks of three trials for combinations of low, moderate, and high anxiety with lists of each variation of intralist similarity of response members: high (HS) (left) and low (LS) (right), Experiment 2.

the interactions between trials and similarity and for trials, similarity, and anxiety were significant at the .05 level or beyond. The nature of these significant interactions is illustrated in Figure 3.

\section{GENERAL DISCUSSION}

A number of predictions based on the relationship between level of drive, according to the Taylor-Spence drive theory, and performance on a PA learning task were made; these were generally not supported.

It was predicted HA subjects would be superior to LA subjects on RL and AM stages because of facilitative effects of drive on both stages of learning. However, increased drive facilitated RL and AM only under conditions of high meaningfulness (Experiment 2); high and low drive had an adverse effect on RL and AM under conditions of low meaningfulness (Experiment 1).

It was predicted under conditions of high response similarity, RL would occur more quickly for HA than for LA subjects. However, in both experiments the interaction between recall condition, anxiety, and similarity was not significant.

It was predicted under conditions of high response similarity and using well integrated response items (e.g., nonsense syllables of high association value, meaningful words), LA subjects would be superior to HA subjects in overall performance. This was not supported in either experiment.

It was predicted at all levels of anxiety, the associative stage would occur more rapidly with a LS response list than with a HS list. In Experiment 1, there was no significant interaction between AM and similarity. In Experiment 2, LS significantly facilitated AM, although this effect diminished over trials.

The present study partially represented a replication of the Levitt and Goss (1961) study with several procedural alterations. In the present study, as Levitt and Goss reported, there was no indication that anxiety interacted with similarity of response members. Results of the present study indicate performance of $\mathrm{AM}$ and RL tasks were better among high-drive rather than low-drive subjects under conditions of high meaningfulness, and high- and low-drive subjects did poorer on RL and AM under conditions of low meaningfulness. There was no significant interaction between anxiety, recall condition, and similarity. Results of the present study did not support the hypothesis that increased drive has a facilitatory effect on the RL stage in PA learning when response competition is high. The results do not support the notion that anxiety and response similarity are significantly related in a paired associate learning task. These findings do not support the Taylor-Spence drive theory.

\section{REFERENCES}

Battig, W. F., \& Montague, W. E. Category norms for verbal items in 56 categories: A replication and extension of the Connecticut category norms. Journal of Experimental Psychology Monograph, 1969, 80(Whole No. 3).

Battig, W. F., \& Spera, A. J. Rated association values of numbers from 0-100. Journal of Verbal Learning and Verbal Behavior, 1962, 1, 200-202.

Glaze, J. A. The association value of non-sense syllables. Journal of Genetic Psychology, 1928, 35, 255-267.

Goulet, L. R. Anxiety (drive) and verbal learning: Implications for research and some methodological considerations. Psychological Bulletin, 1968, 69, 235-247.

Horowitz, L. M. Associative matching and intralist similarities. Psychological Reports, 1962, 10, 751-757.

Jung, J. Two stages of paired-associate learning as a function of intralist response similarity and response meaningfulness. Journal of Experimental Psychology, 1965, 70, 371-378.

L'Abate, L. Manifest anxiety and the learning of syllables with different associative values. American Journal of Psychology, 1959, 72, 107-110.

LevitT, H., \& Goss, A. E. Stimulus attributes and drive in paired-associate learning. Journal of Experimental Psychology, 1961, 62, 243-252.

SPENCE, K. W. Behavior theory and conditioning. New Haven: Yale University Press, 1956.

SPENCE, K. W. A theory of emotionally based drive (D) and its relation to performance in simple learning situations. American Psychologist, 1958, 13, 131-141.

SPIElberger, C. D. Theory and research on anxiety. In C. D. Spielberger (Ed.), Anxiety and behavior. New York: Academic Press, 1966. Pp. 3-20.

TAYLOR, J. A. A personality scale of manifest anxiety. Journal of Abnormal and Social Psychology, 1953, 48. $285-290$.

TAYlor, J. A. Drive theory and manifest anxiety. Psychological Bulletin, 1956, 53, 303-320. 
TAYLOR, J. A. The effects of anxiety level and psychological stress on verbal learning. Journal of Abnormal and Social Psychology, 1958, 57, 55-60.

TAYlor, J. A., \& Chapman, J. P. Anxiety and the learning of paired-associates. American Journal of Psychology, 1955, 68. 671 .

THORNDIKE, E. L., \& LORGE, I. The teacher's word book of 30.000 words. New York: Columbia University Press, 1944.
Underwood, B. J., Runquist, W. N., \& Schulz, R. W. Response learning in paired-associate lists as a function of intralist similarity. Journal of Experimental Psychology, 1959, 58, 70-78.

UNDERWOOD, B. J., \& Schulz, R. W. Meaningfulness and verbal learning. Philadelphia: Lippincott, 1960.

(Received for publication January 10, 1978.) 